\section{Contributors}

\section{Ruth Bastable}

Rbbastable@aol.com

Mike Fitzpatrick is the Higgs Boson of British general practice, conferring mass fitz@easynet.co.uk

Fusun Artiran Igde is assistant professor in Ondokuz Mayis University, School of Medicine, Department of Family Medicine, Samsun, Turkey

\section{fartiran@yahoo.com}

Rukiye Gul is a GP and Director of the Department of Woman Health and Family Planning in Mother-Child Health and Family Planning General Directorate in the Ministry Of Health. Mahir Igde is a paediatrician in Ondokuz Mayis University, School of Medicine, Department of Pediatrie, Samsun, Turkey

Murat Yalcin is assistant professor in Ondokuz Mayis University, School of Medicine, Department of Family Medicine, Samsun, Turkey

All of which drives us to Turkey for WONCA Europe 2008. Book now for Istanbul!

info@woncaeurope2008.org

Chris Johnstone edits hoolet, the glory of RCGP Scotland.

http://www.hoolet.org.uk/

Helen Lester is our new columnist. She qualified in 1985 in Cardiff and works in inner city Birmingham. She is now professor of primary care in Manchester in Martin Roland's unit and is the academic lead of the expert panel that advises the Department of Health and GPC about QOF. Well, hey hoh!!

Helen.Lester@manchester.ac.uk

\section{Ashley Liston}

Qualified Newcastle/Tyne 1982, GP principle since 1986, GP Trainer since 1991, GP Tutor since 2001 ashley.liston@googlemail.com

Igor van Laere is a doctor for homeless people, GGD Ambulant Medisch Team, Dr.Valckenier outreach practice for the homeless, Postbus 2200, 1000 CE Amsterdam, the Netherlands

ivlaere@ggd.amsterdam.nl

His article is dedicated to a great doctor and friend for many homeless people and workers in Amsterdam. Dr. Bart Leewens, for more than a quarter of a century a pillar of trust for those most disadvantaged, sadly passed away at December 12,2007 at the age of 54 . He made a difference.

\section{John Salinsky}

JVSalinsky@aol.com

\title{
On being a proper doctor
}

'My mum's a doctor' number one daughter said to her latest boyfriend, who seemed more interested in the Sunday supper Yorkshire puddings than my career, 'but my dad's a proper doctor.' They were her italics.

The definition of a 'proper doctor' has changed over the centuries to reflect the progress of medicine from an art form to a science. Dr William Henry Welch, one of the founding fathers of medical practice and education in the US, wrote that his father, a practitioner in Norfolk, Connecticut, in the mid-19th century, was able to make people feel better by simply entering the room. 'The art of healing seemed to surround his physical body like an aura: it was often not his treatment but his presence that cured." $\mathrm{He}$ was a proper doctor without the benefit of the 20th century pharmaceutical industry and small group role-play. Nowadays, the specialities with the highest status within medicine, where the proper doctors work, are neurosurgery and thoracic surgery, specialities associated with technologically sophisticated, immediate and invasive procedures in vital organs. ${ }^{2}$

What do our patients mean when they talk of wanting a proper doctor? A systematic review of the literature on patients' priorities for general practice (EUROPEP) $^{3}$ found that the most highly rated aspect of care was 'humaneness', closely followed by 'competence and accuracy.' My son reports that at the Christmas 2007 Medlink course in Nottingham, thousands of prospective medical students were told to be sure to mention that they wanted to be doctors because they liked science and got on well with people (science + people $=$ medicine). So future proper doctors may indeed be just what the patient ordered.

My worry, however, is that in the rush to train scientists who can string sentences together, the often-pilloried idealistic reasons for wanting to be a doctor - to make a difference and help people may become so unfashionable that they disappear altogether. Fifty years ago, Becker's classic study of student culture in medical school in the US ${ }^{4}$ found that $87 \%$ of students gave idealistic answers for why they wanted to be and what it meant to be a doctor, and most maintained their idealism throughout their training. Sinclair's observations of training in 1990s London, by contrast, found a group of students whose initial idealism gave way to institutional cynicism. ${ }^{5}$ But should a proper doctor not be idealistic, want to make a difference, change the world, even in a small way?

And that, of course, may be the rub. I once gave a talk at a medical student conference where most of the 20somethings wanted to work in the developing world as soon as they had qualified. Other platform speakers had helped to build drainage systems in Africa or vaccinated remote tribes. I presented some data on homelessness in Birmingham, stories about people who slept rough within 2 miles of the conference hall, whose average age of death was 42 , who had trench foot and tuberculosis. I ended by suggesting that they might want to consider 'missionary work' in their own city. It was not well received. Being a 'proper doctor' to these idealistic young students meant dramatic intercessional work in difficult international circumstances.

To return to Sunday supper, we threw the notion of a 'proper doctor' around a little and remembered a story from a year or so ago where a patient that my proper doctor husband had been caring for had become suddenly much worse, and whose last words were 'Fetch Dr Lester'. $\mathrm{He}$ arrived 10 minutes later and gently explained to her husband that his wife of some 50 years had died. Mr X walked slowly to the drinks cabinet and brought back two large glasses of whisky with which they toasted her life and sat down together for some time to share stories of her kindness. Mr X's life changed unutterably that day but it was made a little easier by a trusted, kind, and idealistic doctor. Perhaps changing the world can start with the patient in front of you.

\section{REFERENCES}

1. Cousins N. Anatomy of an illness. New York, NY: W.W. Norton and Co., 1979

2. Album D, Westin S. Do diseases have a prestige hierarchy? A survey among physicians and medical students. Soc Sci Med: 2008; 66: 182-188.

3. Wensing M, Jung HP, Mainz J, et al. A systematic review of the literature on patient priorities for general practice care. Part 1: description of the research domain. Soc Sci Med 1998; 47: 1573-1588.

4. Becker H, Geer B, Hughes E, Strauss AI. Boys in white. Chicago, IL: The University of Chicago Press, 1961

5. Sinclair S. Making doctors. An institutional apprenticeship. Oxford: Berg publishers, 1997.

DOI: 10.3399/bjgp08X29919 